\section{Volcano warning needed}

SIR - The recent eruptive activity at Unzen volcano and its tragic consequences emphasize how little the hazards associated with silicic lava flows and domes are appreciated, both by civil defence agencies and volcanologists. Local experts awaited seismic warnings that gas-rich magma was rising through the main conduit; when these warnings failed to materialize, reporters, geologists and citizens of nearby towns assumed that imminent danger had subsided. Although we do not yet know the exact circumstances leading to the deaths of several dozen people, most likely the front of the young lava flow collapsed, allowing gases from the hot interior to expand into an explosive pyroclastic flow. Last month at Colima volcano in Mexico, collapse of a similar flow some distance from the vent also sent block and ash flows many kilometres down a steep valley; fortunately no geologists or civilians were in its path. The same type of activity at Santa Maria volcano in Guatemala over the past year and a half has led to evacuation of many villages in the surrounding valleys, and was probably responsible for killing five thousand people in 1929. Referred to as Merapi-type behaviour, this kind of flow-front collapse has been documented around the world throughout this century.

The failure to recognize the dangers associated with slowly moving viscous lava flows comes partly from the company these extrusions keep. The emergence of silicic lavas is frequently preceded or accompanied by explosive eruptions of magma directly from a vent, as at Mount St Helens in 1980. The simple view of these volcanic systems is that the source magma body is crudely stratified with volatiles; the most water-rich magma at the top erupts first explosively, followed by quieter effusions of drier lava. By the time a viscous dome begins to form, the probability of explosive products coming directly from the vent is markedly reduced. However, as documented by Rose et al. ${ }^{1}$ and explored further by Fink and Manley ${ }^{2}$, the explosive collapse of a silicic flow up to several kilometres from a vent may generate block and ash flows capable of moving rapidly down valleys, scorching everything in their paths.

The reason these late-stage explosions take place relates to the ability of a flow to retain the relatively small amounts of volatiles it contains when it emerges from a vent. Viscous flows with thick carapaces may hold and even concentrate these gases (mostly water, but also sulphur, chlorine and fluorine). Crystallization of the flow interior may expel additional gases. If concentrations become high enough in flows on shallow slopes, volatile pressure may drive explosions which form craters in the flow's upper

1. Fink, J. H. \& Manley, C. R. IAVCEI Proc. Volcanol. 1. 169-179 (1989).

2. Rose, W. I., Pearson, T. \& Bonis, S. Bull. Volcanol. 40. 53-70

(1977).

3. Anderson, S. W. \& Fink, J. H. Nature 341, 521-523 (1989).

NATURE · VOL 351 • 20 JUNE 1991

surface. For flows moving down steep slopes, as at Unzen, Colima and Santa Maria, slumping of the front is common. Rapid exposure and decompression of the hot, gasrich interior can then generate pyroclastic flows with little or no advance warning.

The message for volcanologists, reporters and civil defence officials is that active lava flows of intermediate to felsic compositions should always be viewed as threats to all areas immediately downslope, not just when

\title{
Is the viceroy a batesian mimic?
}

SIR - Mimicry theory proposes that prey species evolve colour patterns similar to those of unpalatable models because they gain protection through the experienced predator's propensity to generalize learnt aversive associations to prey with similar appearances. In a müllerian mimicry ring, participant species are all unpalatable comimics, but in batesian mimicry perfectly palatable prey have evolved mimetic coloration, gaining protection by confusing predators that have had aversive experiences with unpalatable models. The viceroy butterfly, Limenitis archippus (Cramer), has long been regarded as a classic example of batesian mimicry, being apparently palatable yet looking similar to two unpalatable danaine models: the monarch, Danaus plexippus (L.), and queen, Danaus gilippus (Cramer). Ritland and Brower ${ }^{-}$claim to have demonstrated that viceroys are not batesian mimics at all, but unpalatable müllerian co-mimics of the danaines. But there is another interpretation of the results they present that is consistent with the view that viceroys are palatable batesian mimics.

Ritland and Brower presented individual wild-caught red-winged blackbirds, Agelaius phoeniceus (L.) with abdomens of monarchs (model), queens (model), viceroys (putative mimic) and known palatable controls. Birds showed as much aversion to viceroys as to monarchs, and significantly more than to queens, a result taken to indicate that viceroys are unpalatable. But because all the birds received all types of butterfly, they may not have reacted to each in a way that was independent of experience with other species encountered during the experiment (or, in fact, before capture). Presenting only abdomens ensured that birds could not generalize any learnt aversion across the known similarities between species in wing pattern, but visual characteristics are not the only ones over which generalization is possible. The monarch's cardenolide toxins also have a bitter taste ${ }^{2}$ which may become a conditioned signal of toxicity in its own right $^{3}$. If the viceroy also tastes bitter, or similar to the monarch in other ways, then even if it is palatable, birds might still find it aversive because its taste reminds them of the monarch. We should not confuse 'taste' with seismicity suggests the arrival of new magma to the surface, or when rainfall makes mudflows likely. The actual timing of collapse cannot be predicted, although it may be facilitated by earthquakes. Field, laboratory and drilling studies of the volatile contents and emplacement process of older silicic domes $^{3}$ may reveal patterns and clues that can be used to assist future predictions.

Department of Geology,

JONATHAN FINK

Arizona State University,

Tempe,

Arizona 85287-1404, USA

"unpalatability"2. Because 35 per cent of viceroys were apparently 'taste-rejected', evidence on whether they taste similar to monarchs or queens would be illuminating.

Monarchs contain distinctive-smelling pyrazines ${ }^{4}$, which, though not directly aversive to birds, can be.detected by them, and can become conditioned signals of aversive substances $^{5}$. Viceroys are said to smell like monarchs to humans ${ }^{4}$. If this is also true for birds, then birds that have experienced monarchs during or before the experiment might treat viceroys as if they were unpalatable even if they are not.

Wing removal does not control for the potentially confounding effects of similarities in olfactory or taste cues: individual naive birds should be given trials of just one butterfly type, or force-fed with encapsulated butterfly material as has been done for monarchs and queens ${ }^{3}$.

If this alternative interpretation is correct, and the viceroy is a batesian mimic after all, an interesting conclusion follows. Viceroys would have to be mimicking monarchs, and perhaps queens, not just visually, but in at least one other sensory modality (taste or smell) as well. Where multiple mimicry is aimed at a single type of predator (such as birds) it may present novel problems for the evolutionary dynamics of mimicry.

Department of Zoology,

TIM GUILFORD

University of Oxford,

Oxford OX1 3PS, UK

1. Ritland, D. B. \& Brower, L. P. Nature 350, 497-498 (1991) 2. Brower, L. P. in The Biology of Butterflies (eds Vane-Wright, R. I. \& Ackery, P. R.) 109-134 (Academic, London, 1984). Brower, L. P. Scient. Am. 220 (2), 22-29 (1969)

4. Rothschild, M., Moore, B. P. \& Brown, V. Biol. J. Linn. Soc. 23. Rothschild, M., Mo

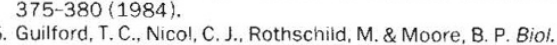
J. Linn. Soc. 31, 113-128 (1987).

SIR - I read with great pleasure that Jane Brower's seminal paper' published in 1958 in which she concluded that the viceroy butterfly was not "either a batesian or müllerian mimic in the classical sense" has at last been confirmed ${ }^{2}$. Most of us working in this delectably controversial field have agreed with Brower, but despite the lapse of 30 years we have all, so far, failed to isolate, let alone identify, the deterrent principle 